\title{
Ensaios Críticos, Vanguarda e Intelectualidade - Guerreiro Ramos, o não Contemporizador
}

\author{
Raul Antelo \\ Universidade Federal de Santa Catarina, Florianópolis, Brasil \\ E-mail:antelo@floripa.com.br
}




\section{Resumo}

Quais foram as circunstâncias históricas e os guias intelectuais que forneceram a Guerreiro Ramos tanto a força para sua crítica da política cultural quanto seus constantes apelos à ação? O propósito principal deste texto é situar as ideias de Guerreiro Ramos no contexto dos argumentos intelectuais de sua época. Tentamos iluminar a relação entre sua incipiente obsessão com o pensamento de Hegel e Nietzsche e seus trabalhos sociais derradeiros.

Palavras-chave: Biografia Intelectual. Política Cultural. Estado Novo.

\section{Abstract}

What were the historical circumstances and intellectual forerunners which provided the impulse for Guerreiro Ramos critique of cultural politics as well as his continued calls for social action? The main purpose of this text is to situate Guerreiro's ideas in the context of the intellectual arguments of the age. We try to illuminate the relationship between Guerreiro's early obsession with both Hegelian and Nietzschean thought and his later social writings.

Keywords: Intellectual Biography. Cultural Politics. Vargas Era. 
— sta intervenção é um peculiar retorno ao passado e um devido $\amalg$ acerto de contas. Em 1980, depois de muitos anos residindo nos Estados Unidos, sem nunca ter retornado ao Brasil, Alberto Guerreiro Ramos (1915-1982) aceitou a proposta de lecionar como professor visitante na Universidade Federal de Santa Catarina. Tinha 65 anos. Pouco antes disso, eu, com menos de 30anos, descobri umas pioneiríssimas páginas de um até então desconhecido Guerreiro Ramos, escritas em 1941, que logo se incorporaram à minha tese de doutorado, Literatura em revista (1981) (Antelo, 1984) ${ }^{1}$. Guerreiro não chegou a assumir o cargo. Faleceu de câncer pouco depois. Eu mesmo, contudo, tendo já defendido a tese, aceitava um cargo de professor visitante na UFSC em 1982. Como tal, como herdeiro de quem não foi, sinto-me hoje, aos 65 anos, na obrigação de prestar uma homenagem a esse pensador muito singular da cultura e do pensamento nacional, em particular.

Com efeito, com pouco mais de 20 anos, em agosto de 1937, Guerreiro Ramos publicou, nas páginas da revista católica A Ordem, editada por Alceu Amoroso Lima, um poema em prosa extremamente eloquente, em sintonia talvez indeliberada com as Teses sobre Feuerbach, de Marx, aquelas que pediam não mais interpretar o mundo, porém, transformá-lo. Murilo Mendes defendia, contemporaneamente, idêntica tese, a de que a premissa surrealista e bretoniana de "changerlavie" era a mesma que

São Paulo aplica ao cristão que deve deixar o homem velho - o homem formalista, o fariseu, que Rimbaud 
justamente detestava - para se revestir do homem novo, que enxergava todas as coisas à luz de Cristo, e assim transformar a sua vida e a do seu próximo. (Mendes, 1937, p. 2)

Guerreiro Ramos, como Murilo, como Mário ou Bandeira, era profundamente marcado pelas ideias de um farol católico daquele tempo, Jacques Maritain, a quem conhecera pessoalmente em Salvador, um ano antes, numa escala da sua viagem ao congresso do PEN Clube, em Buenos Aires. Maritain envolveu-se, nesse congresso, num debate com Giuseppe Ungaretti, católico, porém, fascista. Qual era a posição de Maritain? Considerava, por exemplo, que

El mundo moderno, por malos caminos, ha buscado cosas que eran buenas; se ha emprendido así, durante tres o cuatro siglos, la búsqueda de valores humanos que es preciso salvar ahora mediante un retorno a la verdad más profunda, por medio de una refundición del humanismo clásico. El nuevo humanismo debe sobrepasar al individualismo, prestar atención a las masas, a su derecho al trabajo y a la vida del espíritu. Debe comportar la búsqueda de los valores sociales y de la justicia social, lo que falta en los clásicos de los siglos XVI, XVII y XVIII. (Maritain, 1937, p.133-134)

E, a seguir, Maritain (1937, p. 133-134) se posicionava a respeito da unidade da cultura europeia e ocidental, uma vez que

[...] debemos comprender que la cultura occidental, es decir, nuestra cultura común, común a Europa y América, está en trance de experimentar rupturas fundamentales. No digo que esta ruptura tiene lugar, ni que ella tendrá lugar; digo que amenaza con producirse. Para nuestro mundo occidental, el señor Toynbee, en su Outline of History, distingue dos civilizaciones, las que caracteriza por sus aspectos religiosos: la civilización greco-ortodoxa, que es actualmente objeto de las experiencias comunistas, y la civilización católico-protestante occidental de Europa y de América. Entre esta dos civilizaciones, por lo demás, pueden y deben existir estrechas relaciones; y yo considero a la primera como formando parte del mundo occidental; será deplorable abandonarla al Asia. iPerfectamente! Para volver a las clasificaciones del señor 
Toynbee, si bien es verdad que las diversas formaciones culturales, aunque pertenecientes a otro mundo distinto de la religión, se distinguen las unas de las otras principalmente por los coeficientes religiosos, y ocurriría que la tradición cultural a base católico-protestante de occidente con las transformaciones y la secularización que le ha hecho experimentar la Revolución francesa, por ejemplo, y con todas las alteraciones que se quieran, se encuentra ahora - precisamente a fuerza de ser alterada - frente a formas fundamentalmente diferentes que, por mucho que ellas lograran implantarse en la existencia conservando su diferencia específica, representarían como el resurgimiento de substancias de civilizaciones nuevas.

Os jovens leitores de A Ordem, dentre eles, Guerreiro Ramos, concordariam com essa leitura, simplesmente porque

O que uma parte de minha geração deve, sobretudo, a Maritain é a redescoberta da pessoa humana, êste delicado universo, diante do qual, segundo êle, o próprio Deus se detem, respeitoso. Muitos de nós, hoje, estão desgarrados da linha neo-tomista. Contudo para dar testemunho da presença do mestre de Meudon, basta depôr, tão sòmente, que, ao delinear o caminho da cidade pluralista, nos salvou da tentação do exclusivismo político e, ao afirmar o primado dos valores espirituais, preveniunos contra o perigo da perdição do espírito nas místicas do ressentimento. (Guerreiro Ramos, 1946j, p.145)

Aceitando essa ponderação, vejamos, portanto, esse texto voyou do jovem Guerreiro Ramos nas páginas da revista de Tristão:

Afirmar-se é arriscar-se. E, ao jovem novo, incumbe o papel de afirmar-se, de comprometer-se no que diz e no que escreve. Quando nós atacamos a moral burgueza, a cultura burgueza, todos os vicios, em suma, da civilização contemporanea estamos bem certos de que provocamos a reação daqueles que representam o que combatemos. Mas nem por isso a ação do intelectual novo deve parar. Por isso mesmo é que devemos continuar a ferir e a visar a civilização moderna, num combate de todos os dias, arriscando-nos, pondo-nos em perigo.

O divorcio entre o dizer e o escrever caracteristico do intelectual burguês é uma covardia, é uma demissão do 
homem, revela a falencia da personalidade. A pessoa é, sobretudo, aventurosa. O seu clima é o perigo. Nós vivemos cercados de perigo de todos os lados. E, por isso, temos gosto de viver. Por toda parte a indignidade humana atesta a sua presença. Mas á decomposição de todos os valores humanos e eternos que se observa neste mundo moderno nós temos de opor uma pureza de atitudes e uma inocencia de coração absolutas. Não é, de nenhum modo, desprovido de significação que, sendo este seculo o mais esquecido de Deus e das verdades eternas, tenha sido ele o mundo que viu um Léon Bloy, exemplo admiravel de abnegação de si mesmo, de acordo entre o pensar e o agir, de exaltado amor pela Igreja, que viveu miseravelmente na mais dificil das pobrezas e cuja vida ficou, para nós, constituindo uma lição viva de heroicidade, um Péguy, um Rivière, um Psichari. É deles que nos vem a lição do heroismo.

Sim. Para viver uma vida total, nas condições atuais da civilização, o homem tem de ser um heroi. Na rua, na familia, em nossas relações com o proximo é necessario o heroismo ao homem que se quer conservar fiel a seu Deus e a si mesmo. É preciso ter coragem para que subordinemos, em nós, o individuo á pessoa.

Precisamente o momento que atravessamos é dos mais tragicos de todos os tempos. Nós somos os últimos abencerragens de um mundo que agonisa. A geração atual é profundamente trabalhada pela inquietude. Nós somos uma geração de monstros. Os erros de um mundo pesam dentro de nós, tornando-nos seres complexos, dificeis, incompreensiveis, incoerentes. Somos uma geração de filhos contra pais, de dicipulos contra mestres, de leigos contra clerigos, estamos contra a moral, contra a família burgueza. Contra todos os valores do mundo contemporaneo estão nossas existencias. E só nos pode distinguir esta atitude mais do que nunca inadiavel - a revolta espiritual. Isto é, a luta contra a petrificação, a desmoralização dos mitos modernos. (Guerreiro Ramos, 1937, p. 165-166)

A posição de Guerreiro Ramos é atravessada por um profundo desengano, o mesmo, aliás, que se encontra também em Nietzsche ou Rimbaud, mas caracteriza-se também por um dilaceramento, o drama de ser dois, para retomarmos o título de seu livro de estreia. 
O homem moderno é um ser profundamente desgraçado. E quando ele, um dia, sente que o seu dinamismo é vão, um grande vazio aparece em sua alma. E é quando só o revolver ou o veneno resolve a questão de um destino irrealizado, violado, pela febre do TER. Eu penso que os suicidios que se multiplicam diariamente são causados por esse vazio imenso que o homem moderno encontra dentro de si. Almas vazias, almas mediocres, quem quer que tenha o senso agudo de sua pessoa ha de constatar diante do homem moderno a impossibilidade da COMUNHÃO.

É este fato que torna tragicas as existencias dos homens pessoais. É por isso que todos os genios do seculo XIX foram, como observa Denis de Rougemont, genios negativos, anarquicos, estiveram contra a ordem: Kirkegaard, Rimbaud, Schopenhauer, Baudelaire, Dostoiewski, Nietzsche ${ }^{2}$. Eles encarnam a recusa, o grande NÃO ao conformismo. É necessario que digamos NÃO a todos os assentimentos do mundo moderno. É preciso assumir uma atitude de destruição e de inconformismo diante da ossificação da vida. É preciso tornar a vida incandecente. Violentar o proximo, primeiro, ensinandolhe a descobrir-se como pessoa, a dar um sentido á sua vida subtraindo-se do poder dos mitos modernos.

Nada mais urgente do que esta missão "revolucionaria". Nós cristãos nos afirmamos contra todos os fascismos, contra o comunismo, contra o liberalismo que preconisam um mesmo reformismo institucional pelo qual na base de toda mudança de civilização está uma mudança de regime e não do homem. Eles todos são conformistas, filhos legitimos da filosofia burgueza, do mundo moderno. Nós nos afirmamos pela revolução personalista radical, inteiramente nova e sem taras que visa levar a revolução dentro do proprio homem para dele partir para a mudança dos aparelhos coletivos destinados a servi-lo. O homem é a medida de tudo.

No principio de tudo está o VERBO. E o VERBO é Deus. E, por Deus, proclamamos um NÃO diante de todas as mentiras erigidas em verdades, que informam a civilização contemporanea. (Guerreiro Ramos, 1937, p. 168-169)

Dois anos mais tarde, Guerreiro Ramos completaria a ideia em chave existencialista: 
O homem moderno tem a alma cheia de grampos que o impedem de ser o que é essencialmente. O homem contemporâneo não consente em ser. Aí está a razão de toda a sua angústia. Aí está porque toda literatura contemporânea, em resumo, reflete a ânsia de encontrar um sentido novo para a existência. A deshumanização invadiu todos os setores da atividade humana. (Guerreiro Ramos, 1939, p. 102)

Qual seria o perfil desse jovem baiano que chegava às páginas de $A$ Ordem? De discreta militância integralista, cujos ecos perduram ainda nos anos de 1950, quando lê Teoria y sistema de las formas políticas, do jurista espanhol Francisco Javier Conde, Guerreiro Ramos orientava-se pelo personalismo comunitário de Emmanuel Mounier, o diretor da revista Esprit, e não deve nos surpreender nele que a noção de experiência não se esgote numa simples sensibilidade poética renovada. Guerreiro Ramos começou a elaborar, nesses textos de juventude, a categoria de sujeito epistêmico, como um ser de recusa capaz de conciliar, no entanto, o pensamento e a ação, a existência e o cálculo. Dessa diferenciação provém outra, não só relevante, porém, muito solitária, naquele momento, que se tornou a distinção entre o verdadeiro intelectual e o intelectual ilustrado ou livresco (Guerreiro Ramos, 1941c), que mais adiante se configuraria como a diferença crucial entre a sociologia em hábito e a sociologia em ato, algo que, tendo-o enfrentado a Florestan Fernandes, isto é, polarizando o ISEB contra a sociologia uspiana, atingiria forma definitiva em $A$ redução sociológica, quando Guerreiro argumenta que, nos países periféricos, a redução sociológica só aconteceria com aqueles que tivessem adotado uma posição de engajamento ou de compromisso consciente com o contexto ou, em outras palavras, com aqueles capazes de dizerem Não.

Essa atitude influenciou ainda os novos da década de 1950. Quando, por ocasião do congresso de Assis, em 1961, Laís Correa de Araújo entrevistou Haroldo de Campos, este declara:

Realmente, acredito que a poesia brasileira (como a arquitetura) esteja em fase de exportação de idéias, em amplo processo de descolonização mental, que já se insinuava desde 22. Ao invés de uma defasagem de uma ou algumas décadas em nossos movimentos literários, já 
se é possível cogitar de uma vanguarda (como é o caso da poesia concreta) que o é tarnbém para o consumo internacional. Como adverte Guerreiro Ramos ( $A$ Redução Sociológica, 1958) forma-se, em dadas circunstâncias, uma 'consciência crítica', que já não mais se satisfaz com a importação de objetos culturais acabados', mas cuida de produzir outros objetos nas formas e com as funções adequadas às novas exigências históricas", produção que não é apenas de 'coisas', mas também de idéias. Esse processo é verificável no campo artístico, onde, por exemplo, a poesia concreta operou uma verdadeira 'redução estética', com relação às contribuições de determinados autores que, fundamentalmente, elaboravam a linguagem do tempo, totalizando-as e transforrnando-as sob condições brasileiras, no mesmo sentido em que Guerreiro Ramos fala de uma 'redução tecnológica', na qual 'se registra a compreensão e o domínio do processo de elaboração de um objeto, que permitem uma utilização ativa e criadora da experiência técnica estrangeira'. Daí à exportação o passo é imediato. (II Congresso Brasileiro de Crítica e História Literária, 1963)

A conclusão de Haroldo configurou a hipótese por ele usada para ler a poesia de Oswald de Andrade em "Uma poética da radicalidade", seu prefácio à Poesia Pau Brasil, de 1966 (Estado de Minas, Belo Horizonte, 13 ago. 1961). Ou seja, que a atitude de redução poética não é sem consequências no debate crítico brasileiro. Mas para nós é particularmente relevante destacar que Guerreiro Ramos elaborou essa transformação de paradigma pela primeira vez numa pequena série de textos escritos para a revista Cultura Política, editada pelo Departamento de Imprensa e Propaganda de Vargas, em que, também pela primeira vez no Brasil, ele decidiu abordar o problema do estudo da literatura latino-americana ${ }^{3}$.Seu parti prisera o de que "[...] o Brasil não se pode dissociar do continente americano [...]" (Guerreiro Ramos, 194la, p. 275)e, assim como para os tradicionalistas era imperioso conservar-se à distância da política, para os novos, como ele, no entanto, impunha-se fazer a literatura colaborar com a política, numa obra de construção social (Guerreiro Ramos, 194le, p. 399), alastrando, em outras palavras, a tomada de consciência política e afiançando enfim a identidade nacional. 
Guerreiro Ramos contou com vários subsídios para seu empreendimento: a obra de Pedro Henríquez Ureña, Ángel Rosenblat ${ }^{4}$, Moisés Sáenz ${ }^{5}$, Franz Boas, José Vasconcelos, Haya de la Torre, Rodrigo González Chavez ${ }^{6}$, Ricardo Rojas, Antenor Orrego ${ }^{7}$, Luis Aguilar (Guerreiro Ramos, 1941d, p. 299). Mas uma das fontes mais profícuas, para tanto, foi um autor então quase completamente desconhecido no Brasil: José Carlos Mariátegui ${ }^{8}$. Recorda-se que, logo no início do último dos Sete ensaios de interpretação da realidade peruana, Mariátegui (1972, p. 229) definia-se em função de uma vontade afirmativa, já que seu temperamento era construtivo, e nada havia, a seu ver, de mais antitético que o boêmio puramente iconoclasta e dissolvente; daí que a sua missão diante do passado só pudesse ser a de votar contra, dizer Não. Num plano geral, Mariátegui (1972, p. 234) entendia que a emergência das literaturas nacionais coincidia, no Ocidente, com a afirmação política da ideia do nacional, integrando um movimento que, por meio da Reforma e do Renascimento, criou os fatores ideológicos e espirituais da revolução liberal e de ordem capitalista, do que concluía que o caráter nacional de uma literatura era, portanto, "[...] um fenômeno da mais pura tradição política, estranho à concepção estética da arte". Não sendo temporal, a definição da nação também não era uma materialidade concreta, porém, uma construção de linguagem, “[...] uma alegoria, um mito, que não corresponde a uma realidade constante e precisa, cientificamente determinável" (Mariátegui, 1972, p. 235). Definindo então a literatura peruana pelo seu caráter de exceção ${ }^{9}$, Mariátegui preferiu não sistematizar seu estudo conforme a classificação marxista, em literatura feudal ou aristocrática, burguesa e proletária. Inclinou-se, porém, por um sistema de crítica e de história artística, que lhe garantisse a autonomia artística e, nesse sentido, entendia-o como um método de explicação e de ordenação.

Uma teoria moderna - literária, não-sociológica - sobre o processo normal da literatura de um povo distingue nele três períodos: um período colonial, um período cosmopolita, um período nacional. Durante o primeiro período, um povo, literalmente, não é senão uma colônia, uma dependência de outro. Durante o segundo período, assimilam simultaneamente elementos de diversas literaturas estrangeiras. No terceiro, sua própria 
personalidade e seu próprio sentimento alcançam uma expressão bem modulada. (Mariátegui, 1972, p. 239)

A escolha de Mariátegui coincidia ipsis litteris com a que, no Brasil, formulara Mário de Andrade, daí que não surpreenda a Guerreiro Ramos (1941d, p. 299) reconhecer que

Lendo, há dias, um agudo ensaio de Mário de Andrade sobre a música no Brasil ${ }^{10}$, lá encontrei, aplicada àquela arte, uma observação que sempre nos nortear anos estudos sobre a formação literária nacional em que estamos trabalhando. Diz o escritor paulista que a música brasileira, aliás como toda a música americana, tem um drama particular que é preciso compreender para compreendê-la. Ela não teve [...] essa felicidade que tiveram as mais antigas escolas musicais européias, bem como as musicas das grandes civilizações asiáticas, de um desenvolvimento por assim dizer inconsciente, ou pelo menos, mais livre de preocupações quanto à sua afirmação nacional e social. Fenômenos, aliás, que se observa "com freqüência nas civilizações de empréstimo, mais ou menos desenvolvidas artificialmente e à força, como é o caso de nossas civilizações americanas".

Guerreiro Ramos não rompe, como se vê, com a tradição da autonomia. De fato, na segunda contribuição da série, em junho de 1941, apoiado em The storyofamericanliterature (1939), obra de um crítico judeu-americano, Ludwig Lewinsohn, tradutor, entre outros de $A$ arte $e$ o artista de Otto Rank, Guerreiro Ramos definia uma obra literária como autenticamente nacional, só quando ela atendesse a determinadas características que tinham como meta o aparecimento do herói criador, algo que, estando em Maritain, passou para vários de seus leitores brasileiros. Baste pensar na diferenciação entre artista e artesão que alimenta um famoso ensaio de Mário de Andrade. Por isso mesmo, Guerreiro Ramos (1941b, p. 247) nos propõe um corpus reconfigurado:

I) A literatura dos espanhóis na América e dos cronistas portugueses, nocaso do Brasil, só nos interessa como documento puramente histórico. Procurando-se na literatura o espírito da cultura, (no sentido germânico do vocábulo), as obras dos autores espanhóis e portugueses 
da conquista e da colônia pertencem literalmente aos países de origem. Assim, um Gonzalo Jimenez de Quesada é menos um escritor colombiano do que espanhol ${ }^{11}$. Na vida colombiana é um mero acidente. Se o seu navio tivesse dado nas costas da China e lá escrevesse um livro, não deveria ser considerado, por isso, escritor chinês.

II) A literatura dos escritores nacionais que assimilaram o espírito da metrópole é alguma coisa falsa, híbrida, que, muitas vezes, trái a nossa realidade em vez de representar um esforço para exprimi-la. Tal literatura épura virtuosidade, um sofisma.

III) As literaturas nacionais começam com o aparecimento do espírito criador, dos homens que escreveram por vocação e que se ligaram à terra, não só pela inteligência, mas sobretudo, pelo sangue, pela "paixão".

Por outro lado, Guerreiro Ramos questionava a periodização evolutiva e positiva, na medida em que colocava em crise a noção de progresso, dado central de todo pensamento acerca do contemporâneo. Já no primeiro artigo da série latino-americana, Guerreiro Ramos adota uma categorização que, levando em conta a relação entre campo literário e instituição política de uma nação, preferia, como Nelson Werneck Sodré, seu colega, aliás, nas páginas de Cultura Política e, mais tarde, no ISEB, ver o processo por meio do conceito de etapa. Atravessar-se-ia, assim, a etapa colonial, cujas principais contribuições encontravam-se na forma do sermão, a crônica e a elegia; depois, a etapa romântica, cuja importância não era bem estética, “[...] mas também política e até filosófica, sob cuja influência as nacionalidades americanas tomaram consciência de si mesmas e começou, em literatura, a experiência afetiva da terra $[\ldots]^{\prime \prime}$; e, por último, a etapa contemporânea, definindo para a América "[...] suas formas genuínas para dizer-se". Veja-se que esse esquema tripartite permanecerá ainda válido nos anos de 1970, quando Antonio Candido periodize as relações entre literatura e subdesenvolvimento também em três etapas, a da consciência amena do atraso, a da consciência dilacerada de subdesenvolvimento e a do ultrapassamento dessas determinações, isto é, a da autêntica e singular autonomia. Mesmo assim, é possível destacar que, conquanto avalie positivamente a obra de Sarmiento, por exemplo, Guerreiro Ramos é 
muito crítico da famosa dicotomia civilização versus barbárie e defende, no entanto, certa compreensão da raça cósmica (Vasconcelos), que é a forma por ele encontrada então para exprimir a problemática do negro no Brasil.

Civilização e barbárie são julgamentos de valor que repugnam aos sociólogos modernos, e é cada vez mais empolgante a idéia de que a cada sociedade humana corresponde um ciclo cultural com suas leis e ritmos de evolução próprios. Isto quer dizer que à proporção que a sociologia caminha para um estado de ciência objetiva e não conjetural, o critério ocidentalizante de civilização se desmoraliza. É ainda este preconceito da superioridade do Ocidente que se percebe no sistema de Vierkandt que divide os povos em três grandes grupos: Naturvölker ou primitivos, Kalbkulturvölker ou semicivilizados e Kulturvölker ou civilizados, incluindo entre estes, apenas os europeus ocidentais e os gregos antigos, ao passo que um Toynbee, refletindo já a nova metodologia reconhece, no mundo atual, cinco civilizações vivas: a chinesa e extremo-oriental, a hindú, a islâmica, a ocidental e a ortodoxa ou grego-russa. Neste último, si bem que mais historiador do que sociólogo, está implícito o postulado da escola "ciclo-cultural" ou "histórico-geográfica" (Biasutti) de que não há uma diferença de gráu entre as civilizações e sim de espécie. Creio que foi este novo estado de espírito científico que tornou possível a renovação dos processos de estudos sobre a formação americana. Na América Espanhola, o indologia [sic] tão importante para a compreensão da Colonia, se desenvolveu sob esta atmosfera. E hoje o problema do indígena está sendo colocado de maneira racional e objetiva e não romântica, como até bem pouco. Dir-se-ia mesmo que o indio não constituia um problema. Ela era quando muito, um tema de literatura, de sentimentalismo ou patriotadas inconsequentes. (Guerreiro Ramos, 1941d, p. 301)

Cabe salientar, portanto, que Guerreiro Ramos, crítico agudo, como Mariátegui, das posições democrático-liberais, suspeitava já de certo caráter evolutivo na noção de processo e, em compensação, sugeria o conceito muito mais agudo de cena. Com ele emergia a noção de força (e não de forma ideal) e, portanto, de antagonismo, que ele capta na teoria psicodramática de Jacob Levy Moreno, teoria da cena 
que, reconfigurada pela psicanálise lacaniana, se tornaria mais tarde uma peça central nos trabalhos sobre emancipação de Laclau e Mouffe. Com efeito, o discurso colonial configura, a seu ver, um teatro de representações discordantes, que levam em consideração a divisão da própria subjetividade.

Pois bem, do ponto de vista sociológico, a formação e o processo das culturas americanas têm sido dramáticos, nisto que representam a luta de duas correntes psíquicas, nem sempre complementares, como quer Antenor Orrego, mas antagônicas. Trata-se de um conflito de valores de cultura. Os dois personagens do drama americano são os valores autóctones (constituído pelo repertório de idéias, noções, conceitos e habilidades técnicas do índio e do mestiço de sangue indígena)e os valores coloniais que são os mesmos europeus adaptados às contingências americanas. A dinâmica de nossas civilizações consiste nas desencontradas manifestações de duas mentalidades que coexistem nelas. Sociologicamente, a Colônia ainda não terminou. A mentalidade dos povos americanos ainda é tipicamente colonial. (Guerreiro Ramos, 1941d, p. 299) ${ }^{12}$.

Ora, o colonialismo não é, portanto, apenas uma "fase histórica", com início e fim, mas, "[...] um estado de fato psico-social, um verdadeiro complexo coletivo que consiste na consciência de uma inferioridade diante do estrangeiro" (Guerreiro Ramos, 1941d, p. 300). Daí que Guerreiro Ramos sustente, por exemplo, uma diferença de natureza entre movimentos semelhantes, na Europa e na América.

Mas o romantismo americano não é uma simples reflexão do seu símile europeu, como já assinalou um crítico brasileiro, Tasso da Silveira. É antes uma refração. Enquanto o romantismo europeu permanece, sobretudo, nos domínios da estética, o nosso ultrapassa o plano da arte, da literatura, em particular, e adquire um caráter político. É verdade que um Carl Schmitt revelou um romantismo político, na Europa, mas este se desenvolveu num plano distinto do da literatura. Na América do século XIX, as fronteiras entre o político e o literário são menos precisas e um condutor de povos, como Bolivar, é também um professor de idéias, um poeta como Echeverria é também um preconizador da Asociación de Mayo e escreve 
um livro que se chama Dogma Socialista e, ainda, um Sarmiento pretende derrubar um regime, não somente com armas, mas com o Facundo. (Guerreiro Ramos, 1941d, p. 280-281).

Apoiado, portanto, em O problema nacional brasileiro, de Alberto Torres $^{13}$, Guerreiro entende então ser errado o pressuposto do desaparecimento do colonialismo, tanto no Brasil quanto nos outros países da América, pelo simples trânsito formal à república. O problema, como analisaria, aliás, Homi Bhabha muito depois, é o mimetismo ${ }^{14}$.

Se em literatura, por exemplo, o que caracteriza a Colônia é o formalismo [...],ou na frase de um arguto ensaísta paraguaio, o mimetismo intelectual ${ }^{15}$, o culto da forma cristalizada de uma cultura que não é a nossa, tal tendência continua muito forte e presente em nosso temperamento para ser negligenciada. Ainda sofremos daquela vergonha de ser que levava os americanos de nossos primeiros séculos a se esconderem nas tocas de sua alma. O granfino de nossas capitais é o legítimo símile dos botocudos basbaques diante do estranho europeu que lhe desbrenhava as matas. Somos muito postiços para pretender uma autonomia intelectual. Convém avisar, aliás, que as considerações acima não significam nenhum derrotismo de nossa parte. Estamos simplesmente constatando um fato. Até porque tomar conciencia de um defeito é principiar a removê-lo. O forte movimento quese observa na América no sentido de procurar suas proprias tradições e seus proprios caminhos está a exigir dos seus pensadores uma revisão de todos os quadros de vida. Cabe às gerações atuais uma tarefa de creação. Uma nacionalidade é um trabalho de creação. Quase poderíamos dizer que, na América, as nações existem em estado de direito e não em estado de fato, uma vez que à nossa independência histórica não corresponde uma independência psico-social, por assim dizer. (Guerreiro Ramos, 1941d, p. 300) $)^{16}$

Mas como avaliar esse fator psicossocial? Diga-se, de início que a sensibilidade de Guerreiro Ramos com relação à história traduz-se, a rigor, como uma questão poética, vinculada ao modo de refazer a experiência (Guerreiro Ramos, 1946b) ${ }^{17}$. 
O ofício da poesia exige a recuperação dos dons perdidos, daqueles primitivos dons que no animal estão intactos e também nos personagens bíblicos que comerciavam, sem espanto, com os anjos. (Guerreiro Ramos, 1946i)

Não em vão, Guerreiro recolhe uma confidência de Rilke a uma amiga, que não só ilumina a gênese das Elegias de Duíno, então traduzidas por Dora Ferreira da Silva, mas poder-se-ia pensar até que elas explicam a lógica do próprio método crítico de Guerreiro.

Certa vez, diante de uma vetusta oliveira, em Duino, [Rilke] teve a impressão de ter 'transposto o umbral', 'de encontrar-se em uma outra existência e de que tudo o que ali tinha uma vez vivido, uma vez amado, uma vez sofrido retornava, rodeava-o, apertava-se contra ele, queria de novo pertencer-lhe, queria reviver nele sofrer de novo e amar ainda... O tempo, abolido subitamente, não lhe permitiu mais distinguir o passado reaparecido, do presente vago e sinistro. Alegrias mortas, dores antigas queriam renascer, dar-se-lhe, a atmosfera inteira parecia respirar uma outra vida desconhecida, não obstante familiar, e da qual ele mesmo fazia parte. (Guerreiro Ramos, 1946e)

A ideia relaciona-se com o conceito de morte própria que, a partir de Rilke, será desenvolvido por Heidegger, e que se opõe à morte em massa, a que se praticava então nos campos, assunto que, contemporaneamente, ocupava também filósofos como Walter Benjamin (1985, p. 222-232) ou Carlos Astrada (1940) ${ }^{18}$. E, em última instância, ela prepara as considerações biopolíticas de Agamben (2013) em $O$ aberto. A propósito, em seu ensaio sobre a arqueologia da glória, Agamben resgata um estudo de Furio Jesi, dedicado às Elegias de Duíno, precisamente, em que Jesi aventa a hipótese de que esse retorno à elegia prova a mais absoluta ausência de conteúdo celebratório da história e, em consequência, da poesia moderna e, assim sendo, o que define esse retorno seria a existência de uma máquina antropológico-política, girando no vácuo e solicitando àqueles a que se lhes aplica a mais absoluta servidão voluntária ${ }^{19}$. Foi Rilke, portanto, quem, entre outros, permitiu a Guerreiro chegar a uma crítica da racionalização extensiva ${ }^{20}$. Mas é profundamente sintomático também que tenha sido seu exame 
da literatura latino-americana, como processo tragicamente civilizatório, o que, em última análise, lhe facultou chegar a um diagnóstico social da arte moderna. Em outras palavras, não é a modernidade que lhe permitiu a Guerreiro entender a América Latina, mas, ao contrário, foi a América Latina, como cultura heterogênea, que lhe abriu a possibilidade de formular uma leitura antropológico-política da cultura ocidental moderna.

É fácil compreender que numa sociedade primitiva o gosto de cada pessoa é idêntico ao de qualquer outra. Em nossa sociedade industrial, porém, ele se multiplica em formas variadas, em virtude de sua heterogeneidade. Essa heterogeneidade é resultante da justaposição de sobrevivências como também da própria variedade de perspectivas dos grupos atuais, pois sabe-se, hoje, que o pensamento não é uma cópia neutra, mas uma deformação das coisas. A arte está, como a política, matizada de nuanças ideológicas.

O conflito das vivências estéticas se torna ainda mais agravado pelo fenômeno que se poderia chamar de purificação da arte. A música pura, a pintura pura e outras expressões semelhantes têm sido slogans de correntes que pretendem eliminar o elemento passional da obra de arte e converter o trabalho, a técnica, na própria operação artística. Há dias vimos um poeta brasileiro (João Cabral de Melo Neto) exprimir desassombradamente este ponto de vista, com uma clareza poucas vezes excedida (Guerreiro Ramos, 1946g) (1) $^{21}$

Por esse motivo, a leitura de Guerreiro Ramos não é redentora, no sentido em que a arte, numa perspectiva de restauração ou redenção, suspenderia o tempo histórico e postularia, no extremo, o tempo messiânico. Guerreiro, porém, inclina-se por uma racionalização desalienadora ${ }^{22}$, crítica da ideologia, inspirada em "Nietzsche, com as suas indicações sobre o ressentimento e a moral cristã, Pareto, com sua teoria das ações sociais, Sorel, Karl Marx eEngels, Durkheim, Levy-Brühl, Max Weber, MaxScheler, Freud, Sorokin²3 e Karl Mannheim" (Guerreiro Ramos, 1946d). Guerreiro Ramos ainda cita os trabalhos de "Erich Fromm sobre a doutrina de Freud e sua correspondência com a sociedade burguesa; o de N. Pastore ${ }^{24}$, sobre a influência das tendências políticas sobre a consideração da controvérsia nature - nurture, o de William F. Fontaine ${ }^{25}$, sobre a 'determinação social das obras dos 
professores de cor' (vide Sociology of Knowledge, Robert K. Merton)". Teve acesso pioneiro a um clássico como The Sociology of Literary Taste de Levin Schücking. Lia, sistemáticamente, a Revista de Ocidente de Ortega y Gasset e conhecia, mesmo nos anos de 1940, a História da Sociologia de Francisco Ayala, A cultura do Renascimento na Itália de Jacob Burchhardt, ouos clássicos de Carl Schmitt ou Oswald Spengler, bem como ensaios de Margaret Mead, Georges Canguilhem, Ernst Cassirer, Celso Furtado, Lewis Morgan, George Peter Murdock ou Caio Prado Jr. De modo tal, concluiríamos, que a abordagem de Guerreiro Ramos passa a atender agora, findo já o Estado Novo, e quando, a rigor, começa a contemporaneidade, com o fim da guerra, a uma normalização institucional pautada pelo inclusionismo comunitário e consumista, uma vez que

Toda planificação ideológica conduz necessariamente ao fascismo, ao esmagamento de um grupo por outro, à prática de expurgos e às sangrias sociais, à extrapolação violenta do organismo social. É como antídoto a esta índole ideológica que é oportuno difundir a mentalidade sociológica, verdadeira terapêutica de desfreudização do comportamento social. (Guerreiro Ramos, 1946d)

A inexistência de redenção e a heterogeneidade cultural levam assim Guerreiro Ramos a afirmar que existem diversos tipos de público: em primeiro lugar, os entendidos; a seguir, os filisteus, que se entusiasmam com a arte moderna sem, entretanto, entendê-la ("o filistino é um hipócrita que tem horror de não passar por moderno"); em terceiro lugar, o público marginal, que busca compreender a arte por meio da reeducação estética; e, por último, o público antimodernista, que não só não compreende como até mesmo nega a autenticidade da arte moderna (Guerreiro Ramos, 1946g). Contudo, essa heterogeneidade, na medida em que se desfreudiza, perde sua dimensão antagônica e crítica; abdica assim do político, que, a diferença da política, está atravessado por um incontornável caráter conflitivo. Toda redução sociológica a uma política de consensos, integrada a um corpo definitivo de valores, práticas e decisões determinadas, aliás não muito diversa, repare-se, da que um amigo de adolescência de Guerreiro, o crítico Afrânio Coutinho, difunde, na mesma época, com a incorporação do close reading e da tradição afortunada ${ }^{26}$, passa a ser, em última análise, um 
esquecimento do caráter antagônico, para o qual, em 1937, Guerreiro Ramos encontrara porém uma linguagem contundente: Não.

Há um poema pouco posterior, e muito muriliano, que nos dá a dimensão do pensador Guerreiro Ramos (1936, p. 83), condenado a uma lacuna que, às vezes, interpretamos como punição e outras, porém, como refúgio:

Não tenho grei.

O' meu pai e minha mãe,

O' meu irmão e minha irmã,

$\mathrm{O}^{\prime}$ meus amigos,

Que há de comum entre nós?

Não tenho grei.

No meio de vós estou sozinho.

Até ás profundidades de minha alma não ousareis chegar Porque a aventura é tremenda!

Permaneço sozinho diante do Eterno.

Não nos inquieteis com os meus silencios.

Não vos inquieteis com as minhas fugas inesperadas.

Estou perdido no meio de vós.

Guardei em mim uma paisagem longinqua,

A paisagem da pátria inenarravel

Cuja memoria perdestes na peregrinação pelo pecado.

De lá vim rolando no tempo através de muitas gerações.

Sinto o peso de toda a tristeza do mundo.

Da tristeza de todas as éras.

Embalde me procurareis decifrar.

O' meu pai e minha mãe,

$\mathrm{O}^{\prime}$ meu irmão e minha irmã,

$\mathrm{O}^{\prime}$ meus amigos,

Não sois os da minha grei.

Embalde procurareis seguir-me a róta.

Não contemporisarei convosco.

Vim para dar testemunho.

Vim para vociferar.

Não me julgueis segundo as vossas limitações! 


\section{Notas}

1 Para acompanhar a produção de Guerreiro Ramos nos inícios da carreira, ver, por exemplo, estas obras dele: Introdução à cultura (1939); O 'survey' social (1946); O processo artístico de Rilke (1946); A revolução copernicana da sociologia (1946); A ciência da conduta política (1946); Notas sociológicas sôbre a arte moderna (1946); A Instituição da Liberdade (1947). Sobre o autor, ver Oliveira (1995).

2 Deve se referir a Penseraveclesmains (1936) e ao Journal d'unintellectuelen chômage (1937).

3 "Numa revista de cultura política, como esta, que quer ser uma pesquisa incessante das linhas mestras da nação em todos os setores da cultura e um esforço de penetração em busca do sentido de nossas tradições, que quer, através dos seus quadros, espelhar a vida do país, nos diz a primeira colaboração, seria uma lacuna a ausência de uma seção sobre a literatura latino-americana, um dos aspectos da atividade intelectual por onde é mais fácil o acesso à intimidade dos países irmãos." (Guerreiro Ramos, 194la, p. 275). Na mesma ocasião, esclareceu que “[...] nas futuras crônicas dêste lugar, será sempre considerado que o Brasil não se pode dissociar do continente americano, que exploraremos os planos da literatura latino-americana, ora apresentando uma visão de conjunto sôbre um período, uma época, ora estudando, especialmente, personalidades cujas obras sejam portadoras da teluricidade, da nota continental que nos interessa. Ser-nos-á fácil, numa espécie de método comparado, aproximar a evolução literária americana da formação nacional e encontrar, em uma e outra, pontos de contato que revelem uma semelhança de fisionomia histórica e social [...] Muito de nosso interesse [...] será dirigido para os atuais poetas, romancistas, novelistas, sociólogos e filósofos que, como no Brasil, estão dando ás literaturas de seus países uma individualidade, enriquecendo-as de obras de ambiência genuinamente nacionais."(Guerreiro Ramos, 194la, p. 275).

4 Emigrante, ainda criança, na Argentina, Rosenblat foi discípulo de Henríquez Ureña. Guerreiro devia conhecer sua edição do Amadís de Gaula.

5 Político mexicano; organizou o primeiro congresso indo-americano.

6 Trata-se do folclorista equatoriano Rodrigo Chávez González, defensor das ideias de Vasconcelos.

7 Dele, Guerreiro deve ter lido El Pueblo Continente. Ensayos para una interpretación de América Latina. Santiago de Chile, Ercilla, 1939.

8 Para não dizer que a ausência é completa, conste que o Boletin Titikaka, editado em Puno, entre 1926 e 1930, pelos irmãos Arturo (1898-1969), que assinava Gamaliel Churata, e Alejandro Peralta Miranda (1899-1973), chegou a resenhar a obra de Mário de Andrade, quem por sinal conservou em sua biblioteca o último número da publicação, uma homenagem a Mariátegui.

9 É o conceito chave da biopolítica contemporânea. A exceção não é simples exclusão, porém, é um valor que se relaciona com a norma na forma de uma ausência de aplicação, de tal sorte que o estado de exceção não é o que antecede a ordem, mas a situação decorrente da suspensão da lei. Logo no início de Homo sacer, Agamben nos diz que "La biopolitica è, in questo senso, antica almeno quanto l' eccezione sovrana. Mettendo la vita biologica al centro dei suoi calcoli, lo Stato moderno non fa, allora, che riportare alla luce il vincolo segreto che unisce il potere alla nuda vita, riannodando cosí ( secondo una tenace corrispondenza fra moderno e arcaico che è dato riscontrare negli ambiti piú diversi) col piú immemoriale degli arcana imperii". (Agamben, 1995, p. 9) 
${ }^{10}$ Refere-se, certamente, à "Evolução social da música brasileira" (1939), mais tarde incorporado a Aspectos da música brasileira mas que, em 1941, saiu num caderno pela editora Guaíra de Curitiba, com ilustração de Portinari, enfaixando outro ensaio de Andrade, "Danças dramáticas ibero-americanas". Ambos os ensaios seriam traduzidos pela editora Schapire, em Buenos Aires, em 1944 com o título Música del Brasil.

11 Guerreiro refuta assim o critério de Javier Arango Ferrer, que o coloca como fundador da literatura colombiana em La literatura de Colombia (Buenos Aires, Instituto de Cultura Latinoamericana, 1940). A tese de Arango é a mesma tese que seu colega Afrânio Coutinho esposaria mais adiante em termos de tradição afortunada.

12 Guerreiro Ramos escreveu muitos ensaios abordando não só o determinismo social a serviço da hegemonia, como também reivindicativos da condição subalterna. Entendia que "o negro tem sido estudado entre nós como palha ou como múmia". (Guerreiro Ramos,1950c; Guerreiro Ramos, 1950b; Guerreiro Ramos,1950d; Guerreiro Ramos,1950a; Guerreiro Ramos, 1953a; Guerreiro Ramos,1953e; Guerreiro Ramos, 1953b; Guerreiro Ramos, 1953g; Guerreiro Ramos,1953f; Guerreiro Ramos, 1953d; Guerreiro Ramos, 1953c; Guerreiro Ramos, 1954b; Guerreiro Ramos, 1954a.

13 Retomaria essas ideias em "Considerações sobre o ser nacional". (Jornal do Brasil. Rio de Janeiro, 20 jan. 1957)

14 “O nacionalismo romântico e o regionalismo modernista, a despeito de sua relativa significação brasileira, são, em larga margem, contrapartidas miméticas de correntes intelectuais externas." (Guerreiro Ramos, 1957).

15 Em El Paraguay Eterno (1935), e mesmo através de seus artigos na revista Guarania (1947-8), Juan Natalicio González fixa seu alvo contra o liberalismo ("ladoctrina liberal es el veneno que em ponzoñael alma de lapatria") e dessa posição deriva a condenação ao mimetismo eurocêntrico. Em "América en el mundo de ayer y de hoy", González argumenta que "[...] el mimetismo americano, trascendió de las vanidades nobiliarias a la vida real, a la reverencia de todo lo europeo, para terminar en la enajenación de todo lo nuestro. Advino el imperio de la política europeizante, que en el siglo pasado se tradujo en el culto del capital y del hombre europeos, política que convirtió nuestras libres repúblicas en otras tantas factorías" (Latinoamérica, 1979, p. 15). Discrimina-se assim o mimetismo da simulação teorizada por Ingenieros. Mariátegui, severamente andino, ainda tomava as ideias deterministas de Ingenieros bastante a sério, mesmo ponderando que "Ingenieros, no fundo, permanecia demasiadamente fiel ao racionalismo e ao criticismo dessa época de plenitude da ordem demo-liberal. Esse racionalismo e criticismo conduzem geralmente ao ceticismo e são adversos ao pathos da revolução." (Mariátegui, 2005, p. 129).

16 A fonte declarada, em rodapé, é Proceso y Formación de la Cultura Paraguaya (1938) de Juan Natalicio González, que Guerreiro define como um Gilberto Freyre do Paraguai. Outro tanto se dá com a questão indígena. Baseando-se nos livros do colombiano Antonio Garcia Nossa, Pasado y presente del índio (1939) e da argentina Aída Cometta Manzoni, El índio enla poesia de América española, do mesmo ano, Guerreiro Ramos destaca questões tais como a da racionalização, que compreende a orientação técnica e a adaptação da comunidade indígena às condições do mercado; a questão da integração nacional, incorporando os ameríndios à vida nacional, sem entretanto destruir sua tradição cultural específica; e, por último, a questão das políticas ativas, que passam pelo fornecimento de créditos, abandonando as simples medidas legais de protecionismo. Ver Guerreiro Ramos (1941e, p. 402). 
17 Radicalizada, a questão retornará, como différance, no pensamento de Derrida.

18 "La idea de la muerte propia entraña, para Rilke, la necesidad de oponer a la generalidad abstracta de la muerte, como algo transcendente y externo a la vida, la muerte individual. Es decir, que cada cual ha de tener una muerte de acuerdo con lo que se es o se hubiera llegado a ser". (Astrada, 1940). Astrada era amigo de Vicente Ferreira da Silva, próximo de Guerreiro, e manteria, mais tarde, estreita colaboração com intelectuais do ISEB, Roland Corbisier, Hélio Jaguaribe, Djacir Menezes, Luis Washington Vita ou Efraín Tomás Bó, a quem Guerreiro Ramos dedica, aliás, Uma introdução ao histórico da organização racional do trabalho (Brasília, Conselho Federal de Administração, 2008), tese por ele apresentada a um concurso no DASP, em 1949.

19 "In un progetto di prefazione per un'edizione delle Elegie che non vide mai la luce, Furio Jesi, che ha dedicato alla lettura di Rilke degli studi esemplari, rovesciando l'abituale tendenza della critica a scorgere nelle Elegie un contenuto dottrinale eccezionalmente ricco, si chiede se abbia senso parlare in questo caso di un 'contenuto'. Egli propone di mettere fra parentesi il contenuto dottrinale delle Elegie (che è, del resto, una sorta di centone dei luoghi comuni della poesia rilkiana) e di leggerle come una serie di occasioni retoriche per trattenere il poeta al di qua del silenzio. Il poeta vuole parlare, ma ciò che in lui deve parlare è l'inconoscibile. Per questo 'l'eloquio che risuona non ha alcun contenuto: è pura volontà di eloquio. Il contenuto della voce del segreto che infine risuona non è altro che il fatto che il segreto parla. Perché questo accada, è necessario che le modalità di eloquio siano decantate da ogni contenuto, e lo siano in termini totalizzanti, tali da conchiudere in un punto tutta l'attività trascorsa, tutte le parole pronunciate. Di qui l'organizzazione nel contesto delle Elegie della moltitudine di luoghi comuni rilkiani, anche i più vecchi. Ma di qui, anche, la necessità che esista una qualche sede in cui far confluire i contenuti di questi topoi, afinché nelle Elegie essi possano echeggiare a vuoto... '[Jesi, p. 118.] La definizione jesiana delle Elegie come poesia che non ha nulla da dire, come pura 'asseverazione del nucleo asemantico della parola' (ibid., p. 120) vale, in realtà, per l'inno in generale, essa definisce, cioè, l'intenzione più propria di ogni dossologia. Nel punto in cui coincide perfettamente con la gloria, la lode è senza contenuto, essa culmina nell'amen che non dice nulla, ma soltanto consente e conclude il già detto. E ciò che le Elegie lamentano e, insieme, celebrano (secondo il principio per cui solo nella sfera della celebrazione può darsi lamento) è proprio l'immedicabile assenza di contenuto dell'inno, il girare a vuoto della lingua come forma suprema della glorificazione. L'inno è la radicale disattivazione del linguaggio significante, la parola resa assolutamente inoperosa e, tuttavia, mantenuta come tale nella forma della liturgia." (Agamben, 2006, p. 259-260).

20 "Rainer Maria Rilke, uma das figuras mais representativas desta visão, assim se refere à mecanização da vida: 'Pour nos grand-parents, une maison, une fontaine, une tour familière, jusqu'à leur propre vêtement, leur manteau étaient infiniment plus encore, infiniment plus familières (qu'à nous); chaque chose était um réceptacle dans lequel is trouvaient de l'humain et ajoutaient leur épargne d'humain et ajoutaient leur épargne d'humain. Voici que se pressent vers nous, venues d'Amérique, des choses vides, indifférentes, des apparences de choses, des attrapes de vie... Une maison, dans l'acception américaine, une pomme américaine ou une vigne de lá-bas n'ont rien de commun avec la maison, le fruit, la grappe dans lesquels avaieut pénétré l'espoir et la méditation de nos aïeux... Les choses douées de vie, les choses vécues,lês choses admises dans notre confidence sont sur leur déclin et ne peuvent plus être remplacées. Nous sommes peut-être lês derniers qui 
auront connu de telles choses. Sur nous repose la responsabilité de conserver, non seulement leur souvenir (ce serait peu et on ne pourrait s'y fier), mais leur valeu humaine et larique (larique au sens des divintés de la maison)..." (Pitrou, 1938, p. 96 apud Guerreiro Ramos, 2008, p. 66).

${ }^{21}$ Guerrero Ramos conhecia a distinção, formulada por Ferdinand Tönnies, entre comunidade (Gemeinschaft) e sociedade (Gesellschaft).

22 “Uma vez que perdemos aquele 'Éden intelectual' das épocas culturalmente homogêneas (é à elas que Salvador Dalí se refere quando diz que gostaria de ter nascido num tempo onde não houvesse nada para salvar) a compreensão da arte tende a tornar-se cada vez mais funcional." (Guerreiro Ramos, 1946g).

${ }^{23}$ Pitirim Sorokin, sociólogo russo que chefiou a área de Sociologia em Harvard, era autor de Social and Cultural Dynamics (1937-1941), em que desenvolve uma teoria cíclica do processo social.

${ }^{24}$ Nicholas Pastore (1916-1998) é autor de "The Nature-Nurture Controversy: A Sociological Approach" (in Schooland Society, n. 57, 1943, p. 373-377). Nele, o autor discute a dinâmica entre natureza e nutrição, isto é, se a sociedade determina ou sobre-determina o sujeito. Estudou aspectos comportamentais da psicologia e foi professor no Queens College, na City Universityof New York.

25 William Thomas Valeria Fontaine (1909-1968) foi o primeiro professor afro-americano, na área de Filosofia, na Universidade da Pennsylvania. Dele Guerreiro leu "Social Determination in the Writings of American negro Scholars" (1944). Em 1956, Fontaine assistiu ao congresso de escritores negros, em Paris, junto a Aimé Césaire, Leopold Senghor, Frantz Fanon e James Baldwin. Sua comunicação, "Segregation and Desegregation in the United States: A Philosophical Analysis" não foi bem recebida por muitos dos presentes, dentre eles Fanon, que a julgou muito integrada, muito conservadora.

${ }^{26}$ No final da vida, em consequência da ditadura, que lhe cassa o mandato de deputado pelo PTB, Guerreiro instala-se nos Estados Unidos, onde foi professor na Escola de Administração Pública da University of Southern California, além de ter sido visitante em Wesleyan University e Visiting Fellow de Ciência Política em Yale.

\section{Referências}

AGAMBEN, Giorgio. Homo sacer: Il potere sovrano e la nuda vita I. Turim, Einaudi, 1995.

AGAMBEN, Giorgio. Il regno e la gloria. Vicenza: Neri Pozza, 2006.

AGAMBEN, Giorgio. O Aberto: o Homem e o Animal. Trad. Pedro Mendes; revisão técnica Joel Birman. Rio de Janeiro: Civilização Brasileira, 2013.

ANTELO, Raul. Literatura em revista. São Paulo: Ática, 1984.

ASTRADA, Carlos. La muerte propia. La Nación, Buenos Aires, 14 abr. 1940.

BENJAMIN, Walter. As Teses sobre o conceito de história. In: BENJAMIN, Walter. Obras Escolhidas. São Paulo: Brasiliense, 1985. v. 1. p. 222-232. 
CONGRESSO BRASILEIRO DE CRÍTICA E HISTÓRIA LITERÁRIA. Assis. 24-30 de julho de 1961. Anais... Assis: Faculdade de Filosofia, Ciências e Letras, 1963.

ESTADO DE MINAS, Belo Horizonte, 13 ago. 1961.

GUERREIRO RAMOS, Alberto. A ciência da conduta política. A Manhã, Rio de Janeiro, 21 abr. 1946a.

GUERREIRO RAMOS, Alberto. A hipótese da demora cultural. Suplemento Letras e Artes, n. 1.417. A Manhã, Rio de Janeiro, 24 mar. 1946b.

GUERREIRO RAMOS, Alberto. A Instituição da Liberdade. O Jornal, Rio de Janeiro, Suplemento, 16 fev., 1947.

GUERREIRO RAMOS, Alberto. A revolução copernicana da sociologia.

A Manhã, Rio de Janeiro, 14 abr. 1946c.

GUERREIRO RAMOS, Alberto. A revolução copernicana da sociologia. Suplemento Letras e Artes, n. 1.436. A Manhã, Rio de Janeiro, 14 abr. 1946 d.

GUERREIRO RAMOS, Alberto. Alienação e antropologia. O Jornal, Rio de Janeiro, 8 nov. $1953 a$.

GUERREIRO RAMOS, Alberto. Como nasceram as Elegias de Duino.

Suplemento Letras e Artes, n. 1.423. A Manhã, Rio de Janeiro, 31 mar. 1946 e.

GUERREIRO RAMOS, Alberto. Euclides e a mestiçagem. O Jornal, Rio de Janeiro, 29 nov. 1953b.

GUERREIRO RAMOS, Alberto. Exílio. A Ordem, Rio de Janeiro, v. XVI,p. 83, 1936.

GUERREIRO RAMOS, Alberto. Introdução à cultura. Rio de Janeiro:

Cruzada da Boa Imprensa, 1939.

GUERREIRO RAMOS, Alberto. Literatura latino-americana (I). Cultura

Política, Rio de Janeiro, Ano 1, n. 3, maio 194la.

GUERREIRO RAMOS, Alberto. Literatura latino-americana (II). Cultura

Política, Rio de Janeiro, Ano 1, n. 4, jun. 194lb.

GUERREIRO RAMOS, Alberto. Literatura latino-americana (IV). Cultura

Política, Rio de Janeiro, ano 1, n. 6, ago. 1941c.

GUERREIRO RAMOS, Alberto. Literatura latino-americana (V). Cultura

Política, Rio de Janeiro, Ano 1, n. 7, set. 1941d.

GUERREIRO RAMOS, Alberto. Literatura latino-americana (VII). Cultura

Política, Rio de Janeiro, Ano 1, n. 9, nov. 1941e. 
GUERREIRO RAMOS, Alberto. Não. A Ordem, Rio de Janeiro, v. 17, n. 81, p. 165-166, ago. 1937.

GUERREIRO RAMOS, Alberto. Narcisismo branco do negro brasileiro.

A Manhã, Rio de Janeiro, 12 nov. 1950a.

GUERREIRO RAMOS, Alberto. Nina Rodrigues foi o apologista do branco.

O Jornal, Rio de Janeiro, 20 dez. 1953c.

GUERREIRO RAMOS, Alberto. Notas sociológicas sôbre a arte moderna.

A Manhã, Rio de Janeiro, 28 abr. $1946 f$.

GUERREIRO RAMOS, Alberto. Notas sociológicas sôbre a arte moderna. Suplemento Letras e Artes, n. 1.447. A Manhã, Rio de Janeiro, 28 abr. 1946g.

GUERREIRO RAMOS, Alberto. O negro desde dentro. Revista Forma, n. 3, out. 1954a.

GUERREIRO RAMOS, Alberto. O perigo de um congresso do negro.

A Manhã, Rio de Janeiro, 15 out. 1950b.

GUERREIRO RAMOS, Alberto. O problema da cultura nacional. Jornal do Brasil, Rio de Janeiro, 6 jan. 1957.

GUERREIRO RAMOS, Alberto. O problema do negro na sociologia brasileira. Cadernos de Nosso Tempo, Rio de Janeiro, p. 189-220, jan. 1954b.

GUERREIRO RAMOS, Alberto. O processo artístico de Rilke. A Manhã, Rio de Janeiro, 17 mar. 1946h.

GUERREIRO RAMOS, Alberto. O processo artístico de Rilke. Suplemento Letras e Artes, n.1.411. A Manhã, Rio de Janeiro, 17 mar. 1946i.

GUERREIRO RAMOS, Alberto. O 'survey' social. A Manhã, Rio de Janeiro, 10 mar. 1946e.

GUERREIRO RAMOS, Alberto. Oliveira Viana arianizante. O Jornal, Rio de Janeiro, 13 dez. 1953d.

GUERREIRO RAMOS, Alberto. Os estudos sôbre o negro brasileiro.

A Manhã, Rio de Janeiro, 10 dez. 1950c.

GUERREIRO RAMOS, Alberto. Poemas. A Ordem, Rio de Janeiro, maio 1937.

GUERREIRO RAMOS, Alberto. Presença de Maritain. A Ordem, Rio de Janeiro, ano XXVI, n. 5-6, maio-jun. 1946j.

GUERREIRO RAMOS, Alberto. Senhores e escravos no Brasil. A Manhã, Rio de Janeiro, 22 out. 1950d. 
GUERREIRO RAMOS, Alberto. Sentido da poesia contemporânea.

Cadernos da hora presente, São Paulo, n. 1, p. 102, maio 1939.

GUERREIRO RAMOS, Alberto. Silvio Romero e o negro. O Jornal, Rio de Janeiro, 15 nov. 1953e.

GUERREIRO RAMOS, Alberto. Torres e a mestiçagem. O Jornal, Rio de Janeiro, 6 dez. $1953 f$.

GUERREIRO RAMOS, Alberto. Uma introdução ao histórico da organização racional do trabalho. Brasília, DF: Conselho Federal de Administração, 2008.

GUERREIRO RAMOS, Alberto. Uma redefinição do problema do negro. Diário de Notícias, Rio de Janeiro, 6 dez. 1953 g.

JORNAL DO BRASIL. Rio de Janeiro, 20 jan. 1957.

LATINOAMÉRICA.Cuadernos de cultura latinomericana, n. 82, México, UNAM, 1979.

MARIÁTEGUI, José Carlos. Do sonho às coisas: retratos subversivos. Trad. Luiz Bernardo Pericás. São Paulo, Boitempo, 2005.

MARIÁTEGUI, José Carlos. Siete ensayos de interpretación de la realidad peruana. 25. ed. Lima: Amauta, 1972.

MARITAIN, Jacques et al. Europa - América Latina. Buenos Aires: Comisión Argentina de Cooperación Intelectual, Institut International de Cooperation Intellectuelle, 1937.

MENDES, Murilo. Breton, Rimbaud, Baudelaire. Dom Casmurro, Rio de Janeiro, Ano 1, n. 16, p. 2, 26 ago. 1937.

OLIVEIRA, Lucia Lippi. A Sociologia do Guerreiro. Rio de Janeiro: UFRJ, 1995.

PITROU, Robert. Rainer Maria Rilke. Editiors Albin Michel. Paris. 1938. 